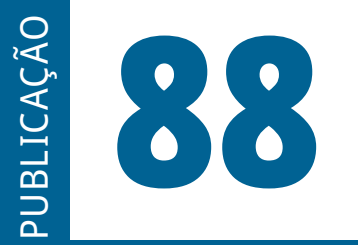

ISSN: 0101-9562

ISSN ELETRÔNICO: 2177-7055

SEQÜÊNCIA

Publicação do

Estudos jurídicos

e políticos

Programa de Pós-Graduação em Direito da UFSC

VOLUME 42 - ANO 2021 
SEQUÊNCIA - ESTUDOS JURÍDICOS E POLÍTICOS é uma publicação temática e de periodicidade quadrimestral, editada pelo Programa de Pós-Graduação Stricto Sensu em Direito da Universidade Federal de Santa Catarina - UFSC.

SEQUÊNCIA - ESTUDOS JURÍDICOS E POLÍTICOS is a thematic publication, printed every four months, edited by the Program in law of the Federal University of Santa Catarina - UFSC.

Versão eletrônica: http://www.periodicos.ufsc.br/index.php/sequencia

A publicação é indexada nas seguintes bases de dados e diretórios/

The Publication is indexed in the following databases and directories:

Base OJS

Base PKP

CCN (Catálogo Coletivo Nacional)

Dialnet

DOAJ (Directory of Open Access Journals)

EBSCOhost

Genamics Journalseek

ICAP (Indexação Compartilhada de Artigos de Periódicos)

Latindex

LivRe!

OJS
PKP
Portal de Periódicos UFSC
Portal do SEER
ProQuest
SciELO
Sherpa/Romeo
Sumarios.org
ULRICH'S
vLex

Ficha catalográfica

Seqüência: Estudos jurídicos e políticos. Universidade Federal de Santa Catarina.

Programa de Pós-Graduação em Direito. n.1 (janeiro 1980)-.

Florianópolis: Fundação José Boiteux. 1980-.

Publicação contínua

Resumo em português e inglês

Versão impressa ISSN 0101-9562

Versão on-line ISSN 2177-7055

1. Ciência jurídica. 2. Teoria política. 3. Filosoia do direito. 4. Periódicos.

I. Universidade Federal de Santa Catarina. Programa de Pós-graduação em

Direito

CDU 34(05)

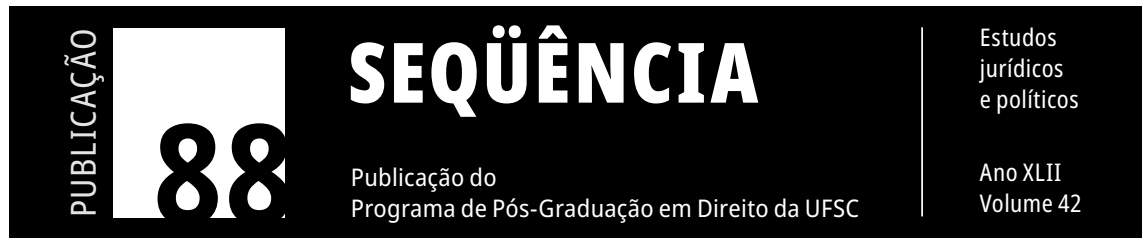




\title{
A fraternidade como antídoto contra a aporofobia
}

\section{The fraternity as antidote against aporophobia}

\author{
Augusto César Leite de Resende \\ Universidade Tiradentes, Aracaju, Brasil \\ Carlos Augusto Alcântara Machado \\ Universidade Tiradentes, \\ Universidade Federal de Sergipe, Aracaju, Brasil
}

RESUMO: Os pobres são vítimas de práticas preconceituosas e discriminatórias, que são expressões de violência e motivadas unicamente pela sua condição econômica. Por essa razão, o tema do presente trabalho científico se inspirou nos estudos de Adela Cortina sobre a aporofobia, termo criado para designar a aversão ao pobre. Nesse contexto, pretende-se, ao longo da presente reflexão, demonstrar, através de uma pesquisa dedutiva e bibliográfica, que os cidadãos são, por força do princípio constitucional da fraternidade, impelidos a adotar práticas fraternas de reconhecimento, respeito e consideração ao pobre e, ao final, sustentar que a fraternidade é um antídoto contra a aporofobia.

PalaVRAS-ChaVE: Aporofobia - Fraternidade - Reconhecimento.

ABSTRACT: The poor are victims of prejudiced and discriminatory practices, which are expressions of violence and motivated solely by their economic condition. For this reason, the theme of the present scientific work was inspired by the studies of the Adela Cortina on aporophobia, a term created to designate aversion of the poor people. In this context, it is intended, throughout this academic reflection, to demonstrate, through deductive and bibliographic research, that citizens are, by virtue of the constitutional principle of fraternity, impelled to adopt fraternal 
practices of recognition, respect and consideration for the poor people and, in the end, maintain that the fraternity is an antidote against aporophobia.

KEYWORDS: Aporophobia - Fraternity - Recognition.

\section{INTRODUÇÃO}

O tema do presente trabalho científico se inspirou nos estudos da Professora de Ética e Filosofia Política da Universidade de Valência, a espanhola Adela Cortina ${ }^{1}$, em seu livro "Aporofobia, el rechazo ao pobre: um desafío para la democracia”. A destacada obra, pois, aborda o tema "aporofobia", termo por ela adotado, criado mesmo, para designar o medo, a aversão ou o rechaço ao pobre, substantivo depois eleito como a palavra do ano de 2017 pela Fundação Espanhola Urgente e já incorporada ao Dicionário de Língua Espanhola.

A aporofobia é uma das fontes de práticas de violência contra o pobre, especialmente em razão da situação de vulnerabilidade que se

1 "Adela Cortina é catedrática de Ética e Filosofia Política na Universidade de Valência, Espanha, onde coordena o curso de pós-graduação em Ética e Democracia. É doutora em Filosofia e foi professora visitante na Universidad de Louvain-la-Neuve, na Bélgica, na Vrije Universitet, em Amsterdam, na Universidade de Notre Dame, nos EUA, e na Universidade de Cambridge, no Reino Unido. Atualmente é diretora da Fundação para a Ética dos Negócios e das Organizações - ÉTNOR. Entre seus livros, destacam-se Razón comunicativa y responsabilidad solidaria (Sígueme, 1985), Ética aplicada y democracia radical (Tecnos, 1993), Alianza y Contrato (Trotta, 2001), Razón pública y éticas aplicadas (Coed., Tecnos, 2003), Ética de la Razón cordial. Educar en la Ciudadanía en el Siglo XXI (Nobel, 2007), Pobreza y Libertad. Erradicar la pobreza desde el enfoque de Amartya Sen (Editores Adela Cortina y Gustavo Pereira, Tecnos, 2009), Neuroética y neuropolítica. Las bases cerebrales de la educación moral (Tecnos, 2011) e ¿Para qué sirve realmente la ética? (Paidós, 2013)”. Informações extraídas da introdução, por Patrícia Fachin, à entrevista concedida ao IHU On-Line no PPG de Economia da UFRS, em 27 de maio de 2016. "Podemos continuar dizendo que cremos na Declaração dos Direitos Humanos? Ou vamos trair a nossa identidade?” Disponível em: http://www.ihu. unisinos.br/entrevistas/555884-podemos-continuar-dizendo-que-cremos-na-declaracaodos-direitos-humanos-ou-vamos-trair-a-nossa-identidade-entrevista-especial-com-adelacortina. Acesso em: 31 mar. 2020. A autora é também conhecida por difundir o que denominou de "Ética da Razão Cordial", título de uma das suas obras mais relevantes. 
encontra o desvalido. Segundo o Instituto Brasileiro de Geografia e Estatísticas - IBGE (BRAsiL, 2018), entre os anos 2016 e 2017, aumentou o percentual de pessoas abaixo da linha de extrema de pobreza global, ou seja, com rendimento domiciliar per capita inferior a US $\$ 1,90$ por dia (ou cerca de $\mathrm{R} \$ 140,00$ mensais em valores de 2017). Somente no ano de 2016, havia 6,6\% da população abaixo desta linha, valor que chegou a 7,4\% em 2017, o que equivale a um aumento de mais de 15 milhões de pessoas em situação de extrema pobreza. O Brasil possuía aproximadamente 55 milhões de pessoas que viviam com menos de R\$ 406 por mês em 2017, vale dizer, em situação de pobreza.

A Assembleia Geral das Nações Unidas aprovou, em 2015, a Agenda 2030 para o Desenvolvimento Sustentável, que inclui dezessete objetivos do desenvolvimento sustentável (ODS), que visam, em última análise, a realizar o desenvolvimento econômico, social e ambiental pelos países subscritores, mediante cooperação e integração entre os Estados e entre os cidadãos. E dentre tais objetivos, destaca-se o ODS 01, que tem como meta "acabar com a pobreza em todas as suas formas, em todos os lugares". Mas a pobreza, lastimavelmente, avança no Brasil e com ela aumentam os casos de violência e ódio aos pobres. Em uma palavra: cresce vertiginosamente a aporofobia.

Nesse contexto, pretende-se, ao longo da presente reflexão acadêmica, demonstrar, através de uma pesquisa dedutiva e bibliográfica, que os cidadãos são, por força do princípio constitucional da fraternidade, impelidos a adotar práticas fraternas de reconhecimento, respeito e consideração ao pobre e, ao final, sustentar que a fraternidade, desde que incentivada e efetivamente praticada, constituir-se-á como um antídoto contra a aporofobia, que, se bem utilizado pelos operadores jurídicos, terá a potencialidade de contribuir para a superação ou impedimento de práticas aporofóbicas.

A metodologia empregada na pesquisa foi uma abordagem dogmática, através de um método dedutivo, que parte de argumentos gerais para argumentos particulares. Primeiramente, foram apresentados os argumentos que se consideram verdadeiros para, em seguida, chegar 
a conclusões formais, já que essas conclusões ficam restritas única e exclusivamente à lógica das premissas estabelecidas (Mezzaroba; Monteiro, 2009, p. 65).

A tipologia de pesquisa foi eminentemente a bibliográfica, elaborada com base em material já publicado e inclui material impresso, notadamente livros e periódicos, bem como material disponibilizado pela internet cuja fonte seja acadêmica e cientificamente relevante e confiável.

\section{APOROFOBIA: A AVERSÃO AO POBRE}

Cortina (2017, p. 11-13) ensina que os espanhóis não têm aversão, medo ou rechaço ao estrangeiro, vale dizer, não são xenófobos, uma vez que a sociedade espanhola, como um todo, acolhe com alegria e satisfação os turistas de outras nacionalidades, etnias e religiões, esforçando-se para recebê-los bem nos hotéis, lojas, restaurantes, praias, ruas e praças das cidades espanholas, identificando-se, ao contrário, um sentimento de xenofilia, ou seja, de amor e amizade a este tipo de estrangeiro, em particular o turista.

Por outro lado, Cortina (2017, p. 12) aponta que a acolhida entusiasmada e hospitaleira dos espanhóis é dirigida unicamente aos turistas que visitam a Espanha dispostos a ali deixar seu dinheiro, eis que não há um sentimento de xenofilia a outra, por assim dizer, categoria de estrangeiros, quais sejam, os refugiados políticos ou imigrantes pobres que fogem de seu país e de seus lares em razão de conflitos armados e étnicos, da fome, miséria, da violência urbana ou catástrofes ambientais e humanitárias, por exemplo. A esse respeito:

Es imposible no comparar la acogida entusiasta y hospitalaria con que se recibe a los extranjeros que vienen como turistas con el rechazo inmisericorde a la oleada de extranjeros pobres. Se les cierran las puertas, se levantan alambradas y murallas, se impide el traspaso de las fronteras. [...] Realmente, no se puede 
llamar xenofilia al sentimiento que despiertan los refugiados políticos y los inmigrantes pobres en ninguno de los países (Cortina, 2017, p. 13)².

As pessoas não adotam, em geral, um comportamento cordial em relação aos estrangeiros pobres, mas também não podem ser adjetivadas indistintamente como xenófobas visto que não são hostis a todo e qualquer tipo de estrangeiro ou forasteiro, pelo simples fato de serem de outra nacionalidade. É importante ressaltar que Cortina (2017, p. 14) não nega a existência da xenofobia e do racismo. A filósofa espanhola apenas fez um recorte em sua reflexão à fobia ao pobre.

$\mathrm{Na}$ verdade, a conduta de aversão e de rechaço está dirigida, como conclui a filósofa espanhola, na obra antes citada, aos pobres e desamparados, isto é, àqueles que poderão causar problemas à sociedade, particular e especialmente por não contribuir com o Produto Interno Bruto (PIB) do país e com bem-estar da população (CORTINA, 2017, p.14). O problema, como é perceptível, apresenta-se exclusivamente quando se destaca o estrangeiro na sua condição específica condição de pobreza.

Para Cortina (2017, p. 11-27), quando não se têm uma palavra ou nomenclatura para designar as coisas ou situações que vivemos, acabam, de fato, não se constituindo ou formando parte do mundo humano, isto pelo fato de que as pessoas precisam reconhecer com palavras as coisas, essencialmente aquelas que não têm existência física, como o amor, a compaixão, o ódio e o medo. A partir dessa premissa, a hostilidade, a rejeição ou aversão ao pobre é cunhada pela autora, como antes referido, de "aporofobia”, fruto da junção do termo grego "áporos", que significa pobre ou sem recursos, com o sufixo "fobia"

2 “É impossível não comparar a recepção entusiástica e hospitaleira com a qual estrangeiros que chegam como turistas são recebidos com a impiedosa rejeição da onda de estrangeiros pobres. As portas estão fechadas, cercas de arame e muros são erguidos, o cruzamento de fronteiras é impedido. [...] $\mathrm{Na}$ verdade, não se pode chamar xenofilia a sensação que refugiados políticos e imigrantes pobres despertam em qualquer um dos países" (tradução livre). 
(Cortina, 2017, p. 23). Nas palavras de Cortina (2017, p. 14), repita-se, a aporofobia se apresenta como o "rechazo, aversión, temor y desprecio hacia el pobre, hacia el desamparado que, al menos en apariencia, no puede devolver nada bueno a cambio"3.

O objetivo da filósofa espanhola - percebe-se claramente - ao dar nome ao medo e à rejeição ao pobre, buscou tornar o fenômeno - se assim pode ser identificado - conhecido pela sociedade e, a partir daí, discutido, prevenido e, mais do que isso, reprimido pelas instituições sociais e políticas (Cortina, 2017, P. 11-27), especialmente por meio do cultivo a justiça e da fraternidade, na medida em que a aporofobia deve ser compreendida como uma patologia social que precisa ser erradicada ou, quando menos, controlada, pois atentatória à dignidade da pessoa humana, enquanto valor intrínseco do homem. Acrescente-se, que tal postura nefasta exclui o pobre do convívio social e político, ao negar-lhe acesso aos bens necessários à sua sobrevivência biológica e social com dignidade (Cortina, 2017, p. 14-15). A propósito:

[...] la aporofobia es un atentado diario, casi invisible, contra la dignidad, el bienser y bienestar de las personas concretas hacia las que se dirige. Pero además porque, como actitud, tiene un alcance universal: todos los seres humanos son aporófobos, y esto tiene raíces cerebrales, pero también sociales, que se pueden y se deben modificar, si es que tomamos en serio al menos eses dos claves de nuestra cultura que son el respeto a la igual dignidad de las personas y la compasión, entendida como la capacidad de percibir el sufrimiento de otros y de comprometerse a evitarlo (CorTina, 2017, p. 15) ${ }^{4}$.

\footnotetext{
Rejeição, aversão, medo e desprezo para com os pobres, para com os desamparados que, pelo menos na aparência, não podem dar nada de bom em troca (tradução livre).

4 " "...] a aporofobia é um ataque diário, quase invisível, contra a dignidade, o ser e o bemestar de pessoas concretas para quem é dirigido. Mas também porque, como atitude, tem um alcance universal: todos os seres humanos são aporofóbicos, e isso tem raízes cerebrais, mas também sociais, que podem e devem ser modificadas, se levarmos a sério pelo menos essas duas chaves da nossa cultura que é o respeito pela igual dignidade
} 
A aporofobia é uma das fontes de práticas de violência contra o pobre, notadamente em razão da situação de vulnerabilidade que se encontra o desvalido (Cortina, 2017, p. 30-31). E, infelizmente, esta patologia é uma realidade brasileira. Numerosos são os casos de violência contra pedintes, miseráveis ou pessoas em situação de rua, que passam desapercebidas por grande parcela da população nacional, praticamente esquecidas e invisíveis aos olhos do Estado e da sociedade. Nas precisas lições de Cabral Júnior e de Costa (2017, p. 31), os pobres, em especial as pessoas em situação de rua,

[.. jazem em esquecimento em um processo dividido em três etapas: primeiro, desqualificam-se ditas pessoas através de um discurso que as associa à desordem e à insegurança, legitimando a ruptura do contrato social em relação a elas; segundo, a sociedade desvincula-se delas, rejeitando-as e isolando-as, pois improdutivas; e terceiro, elimina-se tal população seja extremamente por intermédio de um extermínio físico, seja pela esterilização, seja pelo genocídio cultural, entre outros.

Além da violência,

O excluído social sobrevive privado de direitos fundamentais para uma vida digna. Sobre ele se abate um estado de exceção de fato que lhe retira direitos básicos da existência humana condenando sua vida a uma sobrevivência indigna que, em muitos casos, conduz diretamente para a morte. A falta de alimentação mínima ou de acesso ao atendimento básico de saúde, por exemplo, leva à morte diária a dezenas de milhares de pessoas em sociedades que têm alimentos suficientes e técnicas de saúde disponíveis para quem pode pagar. A vida do excluído é uma vida nua, um homo sacer reduzido em diversos graus a uma sobrevivência indigna e, em muitos casos, a uma morte certa. Pensemos nas milhares de pessoas que morrem no Brasil, cujas mortes poderiam ser evitadas, simplesmente porque não têm

das pessoas e a compaixão, entendida como a capacidade de perceber o sofrimento dos outros e se comprometer a evitá-lo" (tradução livre). 
o atendimento de saúde necessário. Na vida desses excluídos "a exceção é norma". Vivem em um permanente estado de exceção. Muitas das vezes vêm sobrevivendo numa condição de vida nua por muitas gerações. Na condição dos excluídos a exceção é a norma, porém de uma forma paradoxal e diferente daquela que opera no estado de exceção decretado por uma vontade soberana. É uma exceção que não foi decretada pelo direito. Não há um decreto jurídico ou político suspendendo os direitos dos excluídos. Pelo contrário, eles têm garantidos "formalmente" todos os direitos. Todos os excluídos têm os direitos de cidadania plenamente reconhecidos na formalidade da constituição e da lei. A rigor, para eles não há uma exceção jurídica. Porém é precisamente a presumida garantia formal dos direitos que torna os excluídos invisíveis para o direito. Ao não existir um ato soberano de direito que suspenda os direitos dos excluídos, sua condição de vida nua não é reconhecida pelo direito como um ato de exceção. Como consequência, ele - o direito - não se considera responsável pela sua condição de homo sacer (Ruiz, 2012, p. 24).

O antídoto contra a aporofobia é, nas palavras de Cortina (2017, p. 26), "el respeto activo a la igual dignidad de las personas en la vida cotidiana, que exige el reconocimiento cordial de esa dignidad" ${ }^{5}$, de modo que o combate à aporofobia e, por consequência, a superação da discriminação social e econômica em relação ao pobre devem ser também um compromisso social e pessoal a fomentar uma cultura de igual respeito e consideração ao próximo.

A Constituição Federal de 1988 e os tratados internacionais de direitos humanos consagram a liberdade e a igualdade e a pluralidade, que, se bem aplicados, eliminariam a aporofobia, a xenofobia, a homofobia e o racismo, na medida em que a sua abolição exige respeito mútuo à dignidade das pessoas (Cortina, 2017, p. 62-63). Porém,

5 O respeito ativo pela igual dignidade das pessoas na vida cotidiana, que exige o reconhecimento cordial dessa dignidade (tradução nossa). 
nesse ponto, as normas constitucionais são meramente simbólicas e, portanto, destituídas de eficácia, eis que as pessoas, no geral, ainda adotam comportamentos que se traduzem no abandono, esquecimento ou aversão aos pobres.

O ser humano tem naturalmente um instinto de sobrevivência, de autoproteção biológica, que se expressa no desejo de sobreviver, de suprir as necessidades fisiológicas básicas, tais como beber, comer, respirar ou reproduzir-se, o que induz a pessoa a controlar o seu entorno e a buscar o familiar, a segurança e o conhecido (Cortina, 2017, p. 72).

Nesse contexto, Cortina 2017, p. 73) sustenta que o ser humano é biologicamente aporofóbico, uma vez que é extremamente natural que as pessoas prefiram ou busquem algo familiar, notadamente alguém que compartilhe com ele aspectos sociais, culturais e estéticos, ressaltando, inclusive, a partir de uma perspectiva biológica, que o convívio com o diferente gera insegurança e incômodo às pessoas, apesar de a aversão ao estranho ser negada expressamente por muitos. A esse respeito, complementa a filósofa:

[...] rechazo de los extraños, rechazo de los que no parecen aportar nada de positivo, rechazo de los que perturban la vida y pueden traer problemas. A mi juicio, la aporofobia tiene aquí su raíz biológica, en esa tendencia a poner entre paréntesis lo que percibimos como perturbador (CoRTINA, 2017, p. 73) ${ }^{6}$.

Por outro lado, a filósofa espanhola adverte que o fato de o ser humano ter uma predisposição biológica à aporofobia não significa adotar sempre comportamentos discriminatórios aos pobres porque o cérebro das pessoas consegue avaliar outros fatores que podem reduzir ou eliminar os sentimentos fóbicos (CORTiNA, 2017, p. 73.-74), na medida em que o funcionamento do referido órgão não é neutro

\footnotetext{
6 " "[...] rejeição de estranhos, rejeição daqueles que parecem não contribuir nada de positivo, rejeição daqueles que atrapalham a vida e podem trazer problemas. Na minha opinião, a aporofobia tem sua raiz biológica aqui, nessa tendência de colocar entre parênteses o que percebemos como perturbador" (tradução livre).
} 
nem alheio aos valores existentes na sociedade, sendo capaz, portanto, de tomar decisões a partir da análise de valores negativos ou positivos envolvidos na questão (CORTINA, 2017, p. 69), o que levaria as pessoas, inclusive, a adotar comportamentos solidários, afetivos e de cuidado ao próximo. É dizer: o ser humano está preparado biologicamente tanto para o egoísmo e como para a cooperação (Cortina, 2017, p. 79).

Além disso, a aporofobia tem também uma origem social. As pessoas se relacionam, nos tempos atuais, de um modo geral, com uma expectativa de reciprocidade, no sentido de que os seres humanos cooperam entre si com a esperança ou com o desejo de receber algo em troca, vale dizer, a reciprocidade está na base da cooperação (Cortina, 2017, p. 78-79). Por essa razão,

$Y$ en cada esfera social, los que no pueden devolver los bienes que se intercambian en ella, que pueden ser favores, puestos de trabajos, plazas, dinero, votos, apoyo para ganar unas elecciones, honores y prebendas que satisfacen la vanidad. Éste es el caldo de cultivo, biológico y social, de la aporofobia, de la aversión hacia los áporoi, hacia los que no tienen nada bueno que ofrecer a cambio. Y no sólo si quedan lejos, sino todavía más si están cerca y pueden causar problemas, si pertenecen a la propia familia y se les trata como a una vergüenza que hay que ocultar (Cortina, 2017, p. 81) ${ }^{7}$.

Cortina (2017, p. 24) sugere que para a superação ou minimização da aporofobia é necessário a construção da igualdade a partir da educação, formal e informal, e das instituições e organizações que reforcem o reconhecimento dos pobres. Entretanto, a educação e a

"E em cada esfera social, aqueles que não podem devolver os bens trocados nele, que podem ser favores, empregos, lugares, dinheiro, votos, apoio para ganhar eleições, honrarias e regalias que satisfaçam a vaidade. Este é a fonte, biológica e social, da aporofobia, da aversão ao áporoi, para aqueles que nada têm a oferecer em troca. E não só se eles estão longe, mas ainda mais se eles estão próximos e podem causar problemas, se eles pertencem a uma família e eles são tratados como uma vergonha que deve ser escondida" (tradução livre). 
existência de instituições não são os únicos contravenenos capazes de debelar ou controlar a aporofobia.

A fraternidade também é um antídoto contra a aporofobia, eis que, como diz a própria filósofa espanhola, "no bastan como móviles de la conducta ni el egoísmo ni siquiera el afán de cooperar, es necesario ir más allá de ello, hacia el reconocimiento recíproco de la dignidad y hacia la compasión, que rompe las barreras y se extiende universalmente" (CORTINA, 2017, p. 81) ${ }^{8}$. A adoção de comportamentos fraternos, especialmente dirigidos pelo ordenamento jurídico, tais como a solidariedade, o respeito e a responsabilidade recíproca, reconhecendo o pobre (o desvalido, hipossuficiente economicamente) como irmão, enquanto membro de uma mesma família, a família humana, tem a potencialidade de protegê-lo contra a discriminação.

\section{A FRATERNIDADE COMO ANTÍDOTO CONTRA A APOROFOBIA}

A tríade da Revolução Francesa, consistente na "Liberdade, Igualdade e Fraternidade", influenciou a construção do pensamento jurídico-político moderno, mas a fraternidade não ocupou papel de destaque na cultura ocidental, na medida em que a liberdade e a igualdade foram rapidamente incorporadas nas Constituições como categorias jurídicas e políticas (Fernandes; Pellenz; Bastiani, 2017, p. 160) e a fraternidade se transformado no princípio esquecido. Porém, tem-se, ainda que timidamente, o resgate da fraternidade após a Segunda Guerra Mundial, em especial com o advento da Declaração Universal dos Direitos Humanos de 1948.

"Não é suficiente como motivos de comportamento o egoísmo ou mesmo o desejo de cooperar, é preciso ir além, para o reconhecimento recíproco da dignidade e da compaixão, que rompe barreiras e se estende universalmente" (tradução livre). 
Pizzolato (2008, p. 113-114) aduz que a fraternidade é uma espécie de solidariedade horizontal, distinta da solidariedade vertical, caracterizada, esta, por ser uma forma de intervenção do Estado com o intuito de reduzir as desigualdades sociais e permitir o livre desenvolvimento da pessoa humana. A fraternidade destaca-se como a uma espécie de socorro mútuo entre os próprios indivíduos, sendo o Estado um mero fiador externo.

A fraternidade permite "dar fundamento à ideia de uma comunidade universal, de uma unidade de diferentes, na qual os povos vivam em paz entre si, sem o jugo de um tirano, mas no respeito das próprias identidades" (BAGgio, 2008, p. 53). Mais do que isso, a fraternidade, como registra o Papa Francisco, em discurso proferido por ocasião da comemoração do Dia Mundial da Paz, em 01 de janeiro de 2014, com o título "Fraternidade, fundamento e caminho para a paz", tem a aptidão para promover a paz social, o equilíbrio entre liberdade e justiça, portanto igualdade, entre responsabilidade individual e solidariedade e, ainda, entre bens particulares e bem comum (Igreja Católica, 2014).

A fraternidade, apesar de não ser prevista expressamente no texto formal da Constituição Federal de 1988 (salvo no preâmbulo), como aduz Carlos Augusto Alcântara Machado (2017, p. 219), está positivada implicitamente no ordenamento jurídico brasileiro, apresentando-se como categoria jurídico-constitucional indispensável para o advento do constitucionalismo fraternal. Nesse passo, ainda em companhia do autor, a sociedade fraterna tem "como núcleo a garantia incondicional da dignidade da pessoa humana, do homem todo e de todos os homens, coração dos direitos fundamentais" (Machado, Carlos, 2017, p. 219).

Segundo tal compreensão, a fraternidade é uma categoria jurídica positivada no ordenamento jurídico nacional e extraída do Preâmbulo da Constituição e da própria Carta Magna, quando enunciam valores estruturantes do Estado brasileiro e os objetivos fundamentais da República Federativa do Brasil, dentre os quais, destaca-se, a construção 
de uma sociedade fraterna, pluralista, sem preconceitos, livre, justa e solidária (art. $3^{\circ}, \mathrm{I}-\mathrm{CF}$ ).

Refere Carlos Augusto Alcântara Machado (2017, p. 219), nas conclusões de sua obra específica sobre o tema, que, quando a Constituição brasileira de 1988, no enunciado preambular, destacou os assim identificados "valores supremos de uma sociedade fraterna" (direitos sociais e individuais, liberdade, segurança, bem-estar, desenvolvimento, igualdade e justiça), apresentou "um novo marco civilizatório, desta feita, a partir da fraternidade". Não mais somente da liberdade ou da igualdade.

Nesse contexto, a fraternidade é, enquanto elemento inserido no mundo jurídico, prescritiva, donde se extrai deveres jurídicos de socorro impostos pela legislação ao particular, não se confundindo, portanto, com as formas voluntárias de ajuda ao próximo, como a filantropia (Pizzolato, 2008, p. 114). Assim, a prática da fraternidade pode ser incentivada ou direcionada ou fomentada pela lei ${ }^{9}$.

Segundo Clara Machado (2017, p. 62), o reconhecimento da força normativa da fraternidade a partir de sua consagração no sistema jurídico nacional como regra ou princípio lança novos olhares sobre os direitos e, especialmente sobre os deveres fundamentais. Por isso, a fraternidade enquanto norma jurídica produz efeitos jurídicos no plano do mundo fático.

Nas palavras de Clara Machado (2017, p. 65),

[...] fraternidade possui natureza normativa principiológica, na medida em que está no nível reflexivo da ordem jurídica, servindo tanto para a construção hermenêutica de outras regras, bem como para ordenar, em razão de seu caráter deôntico, que algo seja concretizado, de acordo com as circunstâncias fáticas

\footnotetext{
9 Numa perspectiva diversa, mas sempre associando Direito e Fraternidade, destacam-se as pioneiras lições de Elígio Resta, consubstanciada na obra O Direito Fraterno (2004), particularmente difundidas no nosso meio por Sandra Regina Martini em diversos estudos científicos sobre o tema.
} 
e jurídicas existentes. Defende-se, portanto, que fraternidade é princípio fundamental introduzido de maneira expressa ou implícita no texto constitucional que atua como vetor interpretativo na construção do significado de outros enunciados, além de fomentar no indivíduo o reconhecimento da dignidade humana e realizar o princípio da responsabilidade no âmbito estatal, individual e coletivo.

O princípio (ou regra) da fraternidade obriga os homens a desenvolverem uma atividade que promova o progresso material e espiritual da sociedade, de modo que todos deverão contribuir, de alguma forma, para o bem-estar do outro e da sociedade, na medida em que a fraternidade não significa apenas não prejudicar o próximo, mas, sobretudo, fazer o bem ao outro (Pizzolato, 2008, p. 119-120). A propósito,

Fraternidade permanece sendo um princípio norteador das relações humanas, pois coloca o sujeito que se orienta a partir da Fraternidade como um membro do corpo social, potencialmente capaz de promover a igualdade e o bem-estar dos cidadãos por meio de um olhar horizontal e que promova a alteridade e não a discriminação (Fernandes; Pellens; Bastiani, 2017, p. 163).

A fraternidade está ligada à ideia de dever, isto é, de reconhecer como irmão quem não é irmão de sangue, sobressaindo daí as obrigações de solidariedade, de respeito e de reciprocidade para com o outro (Barzotto, 2018, p. 79-89), que é dotado de igual dignidade. Barzotto (2018, p. 82) leciona que reconhecer a pessoa humana como irmão e, destarte, como membro de uma mesma comunidade, significa assumir a responsabilidade por ele, eis que numa comunidade todos são responsáveis pelo bem de todos, havendo, portanto, um dever de solidariedade para com os demais, vedando-se, por consequência, a indiferença e a omissão.

Além disso, parafraseando Barzotto (2018, p. 84), reconhecer o outro como irmão significa respeitar a sua liberdade, de modo que a adoção de comportamentos aporofóbicos contrários à liberdade do 
outro, especialmente aqueles que neguem a sua liberdade ou condição de sujeito, caracteriza conduta não fraterna e, desse modo, ilícita, na medida em que leva à reificação ou coisificação do pobre.

A fraternidade se traduz ainda no dever de reconhecer o outro, sobretudo o desprovido de recursos financeiros, como igual a si mesmo, reconhecendo-o, assim, como titular dos mesmos direitos e obrigações (BARzotTo, 2018, p. 84-85). Enfim, a fraternidade compreende concorrer positivamente para o progresso material e espiritual da sociedade e das pessoas (Pizzolato, 2008, p. 120-121).

A superação da aporofobia depende, sobretudo, como aponta Cortina (2017, p. 126), do reconhecimento de que o outro, o sem recursos ou pobre, é um igual, com o qual se tem um vínculo que precede a qualquer contrato social ou político, ou seja, um vínculo de irmandade e de humanidade. Nesse contexto, a fraternidade se apresenta como um verdadeiro antídoto contra a aporofobia, na medida em que direciona, como ressaltado alhures, ao reconhecimento, o respeito e a responsabilidade recíproca em relação ao ser humano.

Parafraseando Gabardo (2017, p. 83), a tolerância como instrumento de combate à aporofobia é insuficiente porque excludente, na medida em que, apesar de impor o dever de respeito ao outro, não elimina a indiferença e a distância entre o pobre e o aporofóbico. É mister a fraternidade.

O princípio da fraternidade, na qualidade de categoria jurídica, não permite a aporofobia e exige do Estado e dos cidadãos o respeito ao pobre, enquanto ser humano dotado de dignidade e, portanto, merecedor de igual consideração e respeito. A prática de atos aporofóbicos ou de indiferença ao pobre revela um comportamento não fraterno e, desse modo, atentatório à Constituição, merecendo censura jurídica.

Além do mais, os direitos fundamentais, inclusive o direito à igualdade, são, na lição de Clara Machado (2017, p. 65), protegidos em razão da fraternidade porque este é instrumento normativo de regulação do comportamento individual, que orienta o exercício da liberdade 
e da autonomia privada, devendo o Estado ser fiador da incorporação da fraternidade na liberdade (Pizzolato, 2008, p. 122-123).

Hodiernamente, não mais se discute a força normativa da Carta Magna. Ela é norma jurídica, dotada de imperatividade e que, por isso mesmo, seus preceitos são obrigatórios e vinculativos. No caso do Brasil, a Constituição de 1988 consagra, ainda que implicitamente, o princípio da fraternidade, com aplicabilidade direta e imediata, com vistas a compelir, como bem ensina Clara Machado (2017, p. 66), as pessoas a adotar condutas e atividades que respeitem a dignidade humana e os direitos fundamentais, inclusive e particularmente dos pobres.

A Constituição não é um documento exclusivamente político, mas jurídico e, como tal, dotado de imperatividade. No início da segunda metade do século XX, o Professor alemão Konrad Hesse (1991, p. 19) assentou que:

A Constituição jurídica logra converter-se, ela mesma, em força ativa, que se assenta na natureza singular do presente (individuelle Beschffenheit der Gegenwart). Embora a Constituição não possa, por si só, realizar nada, ela pode impor tarefas.

Partindo-se da premissa de que a fraternidade é positivada na Constituição Federal de 1988, conclui-se, com Carlos Augusto Alcântara Machado (2017, p. 208), que a responsabilidade social entre cidadãos é um decorrência normativo-constitucional da fraternidade e, de acordo com a lição de Clara Machado (2017, p. 66), viabiliza a conscientização e a realização dos direitos e deveres fundamentais dos indivíduos.

A fraternidade se apresenta como princípio ativo, motor do comportamento, da ação dos homens, que impõe, como diz Aquini (2008, p. 133), deveres para com a comunidade e para com o outro, nos termos do art. 29 da Declaração Universal dos Direitos do Homem. O princípio jurídico da fraternidade "responsabiliza cada indivíduo pelo outro e, consequentemente, pelo bem da comunidade, e promove 
a busca de soluções para a aplicação dos direitos humanos que não passam necessariamente, todas, pela autoridade pública" (AQUINI, 2008, p. 138-139), valorizando-se, com isso, o papel das entidades privadas e do próprio cidadão na satisfação dos direitos civis, políticos, sociais, econômicos, culturais e ambientais.

O princípio da fraternidade tem, na qualidade de categoria jurídica, força prescritiva (AQUINI, 2008, p. 140), conduzindo a adoção de comportamentos fraternos para com o pobre - inclusive, como ressalta Clara Machado (2017, p. 66), com o estímulo de condutas, através de sanções positivas e premiais -, e, ao mesmo tempo, proibindo condutas aporofóbicas, pois discriminatórias e indignas. A esse respeito,

La capacidad de contratar no es la única forma que los seres humanos tienen de vincularse entre sí, no vivimos sólo del intercambio, del dar y el recibir. En la base de las relaciones humanas hay un vínculo no establecido voluntariamente, sino que ya existe previamente, y únicamente es posible intentar romper o reforzar. A fin de cuentas, cada persona lo es porque otras la reconocen como persona, el reconocimiento recíproco constituye un vínculo, un ligatio, en la que ya se encuentra, No existe el individuo aislado, sino las personas humanas en vínculo, en relación (Cortina, 2017, p. 100) ${ }^{10}$.

Enfim, "quando um indivíduo recusa-se a ver o outro como um igual, o Direito deve obrigá-lo ao reconhecimento" (GABARDo, 2017, p. 83). Por outro lado, é evidentemente que o simples reconhecimento do dever jurídico de respeito e consideração ao pobre é, por si só, incapaz de provocar uma mudança de comportamento das pessoas.

10 "A capacidade de contratar não é a única maneira pela qual os seres humanos têm que se relacionar, nós não vivemos apenas da troca, do dar e do receber. Na base das relações humanas existe um elo não estabelecido voluntariamente, mas que já existe anteriormente, e só é possível tentar romper ou reforçar. No fim das contas, cada pessoa é porque os outros a reconhecem como uma pessoa, o reconhecimento recíproco constitui um vínculo, um ligatio, em que já se encontra. Não existe o indivíduo isolado, mas as pessoas humanas vinculadas, em relação" (tradução livre). 
É preciso, desse modo, pensar e compreender as funções do Direito na contemporaneidade - particularmente as de caráter promocional - e, em especial, refletir sobre quais instrumentos jurídicos existentes no sistema jurídico nacional, com fundamento no princípio jurídico da fraternidade, poderão ser utilizados para garantir a superação da aporofobia e, consequentemente, para fomentar mudanças de comportamento que permitam criar uma sociedade fraterna e mais justa para todos, tarefa que aqui não será desenvolvida.

A fraternidade se apresenta, portanto, como ensina Baggio (2208, p. 54), a propósito do grande projeto da modernidade, expresso no tríptico revolucionário francês (Liberté, egalité, fraternité), como princípio regulador dos princípios da igualdade e da liberdade. Princípio regulador, pois, "se vivida fraternalmente, a liberdade não se torna arbítrio do mais forte", nem a igualdade se "degenera em igualitarismo opressor".

\section{CONSIDERAÇÕES FINAIS}

O objetivo deste trabalho científico foi o de refletir, a partir de uma pesquisa dedutiva e bibliográfica, sobre o papel do princípio constitucional da fraternidade enquanto antídoto contra a aporofobia. Para tanto, partiu-se da premissa de que a fraternidade está positivada na ordem constitucional brasileira e, por isso, na qualidade de princípio jurídico, impõe ao Estado e aos cidadãos um dever de reconhecer as pessoas, independentemente da condição econômica, como seres humanos dotados de igualdade dignidade e, por isso, de idêntica consideração e respeito.

A aporofobia é uma mal presente nas sociedades contemporâneas, especialmente a nacional, que produz em desfavor dos pobres a violência, a opressão, a indiferença e a humilhação, cuja superação somente será alcançada com a implementação de práticas fraternas, que se traduzam em responsabilidade recíproca, um pelo outro, que consubstanciem a solidariedade e o respeito ao pobre. 
De princípio norteador das relações humanas à categoria jurídica, com fundamento constitucional, o princípio da fraternidade, restou positivado no ordenamento jurídico brasileiro a partir da sua consagração no preâmbulo da Constituição Federal, mas também como decorrente do primeiro objetivo fundamental da República Federativa do Brasil.

Assim, quando a Constituição Federal indica, como primeiro objetivo fundamental da República, no seu art. $3^{\circ}$, I, a construção de uma sociedade, além de livre e justa, nomeadamente solidária, o legislador constituinte referia-se, certamente, como registrou Ayres Britto, em manifestação do voto na ADI 3105-8, julgada em definitivo no dia 18 de agosto de 2004, ao "terceiro valor fundante, ou inspirador da revolução Francesa", é dizer, a fraternidade.

A fraternidade tem a capacidade transformadora da realidade dos pobres, servindo, inclusive, de instrumento de combate à marginalização, de proteção dos desvalidos e de promoção da dignidade dos miseráveis e sem recursos, uma vez que impõe ao Estado e aos cidadãos deveres de tolerância, harmonia, cooperação e respeito ao outro, todos, indistintamente, e ao hipossuficiente economicamente com maior razão, merecedor de igual consideração e respeito.

\section{REFERÊNCIAS}

AQUINI, Marco. Fraternidade e direitos humanos. In: BAGGIO, Antonio Maria (org.). O princípio esquecido/1: a fraternidade na reflexão atual das ciências políticas. Vargem Grande Paulista: Editora Cidade Nova, p. 127-151, 2008.

BAGGIO, Antonio Maria. Introdução. In: BAGGIO, Antonio Maria (org.). O princípio esquecido/1: a fraternidade na reflexão atual das ciências políticas. Vargem Grande Paulista: Editora Cidade Nova, p. 07-24, 2008.

BAGGIO, Antonio Maria. A idéia da fraternidade em duas Revoluções: Paris 1789 e Haiti 1791. In: BAGGIO, Antonio Maria (org.). O princípio 
esquecido/1: a fraternidade na reflexão atual das ciências políticas. Vargem Grande Paulista: Editora Cidade Nova, 2008.

BARZOTTO, Luis Fernando. Fraternidade: uma aproximação conceitual. In: MACHADO, Carlos Augusto Alcântara; JABORANDY, Clara Cardoso Machado; BARZOTTO, Luciane Cardoso (orgs.). Direito e fraternidade: em busca de concretização. Aracaju: EDUNIT, p. 79-89, 2018.

BRASIL. Instituto Brasileiro de Geografia e Estatísticas - IBGE. Síntese de indicadores sociais: uma análise das condições de vida da população brasileira. Rio de Janeiro: IBGE, 2018. Disponível em: https://biblioteca. ibge.gov.br/visualizacao/livros/liv101629.pdf. Acesso em: 15 de maio de 2019.

CABRAL JÚNIOR, Luciano Roberto Gulart; COSTA, Eder Dion de Paula. Violência às pessoas em situação de rua: o direito fundamental à segurança em xeque. Juris, Rio Grande, v. 27, n. 2, p.25-40, 2017.

CORTINA, Adela. "Não são mais os pobres que violam as regras". Entrevista ao GAÚCHAZH - junho 2016. Disponível em : https:// gauchazh.clicrbs.com.br/geral/noticia/2016/06/nao-sao-os-mais-pobres-que-violam-as-regras-diz-filosofa-adela-cortina-5921675.html. Acesso em: 01 abr. 2020.

CORTINA, Adela. Podemos continuar dizendo que cremos na Declaração dos Direitos Humanos? Ou vamos trair a nossa identidade? Entrevista especial com Adela Cortina. Revista IHU - Instituto Humanitas UNISINOS (on line). Edição 535. 03.06.2016. Disponível em: http://www. ihu.unisinos.br/entrevistas/555884-podemos-continuar-dizendo-que-cremos-na-declaracao-dos-direitos-humanos-ou-vamos-trair-a-nossa-identidade-entrevista-especial-com-adela-cortina. Acesso em: 31 mar. 2020.

CORTINA, Adela. No sabemos si la democracia sobrevivirá a internet. Entrevista ao SEMANA, 30 de setembro de 2019. Disponível em: https:// www.semana.com/nacion/articulo/entrevista-con-adela-cortina-creadora-del-termino-aporofobia/634072. Acesso em: 31 mar. 2020.

CORTINA, Adela. Aporofobia, el rechazo al pobre: un desafío para la democracia. Barcelona: Paidos, 2017.

FERNANDES, Sérgio Ricardo Aquino; PELLENZ, Mayara; BASTIANI, Ana Cristina Bacega de. Fraternidade como alternativa à seletividade do direito penal. Sequência, Florianópolis, n. 76, p. 155-182, ago. 2017. 
GABARDO, Emerson. Os perigos do moralismo político e a necessidade de defesa do direito posto na Constituição da República de 1988. A\&C Revista de Direito Administrativo \& Constitucional, Belo Horizonte, ano 17, n. 70, p. 65-91, out./dez. 2017.

HESSE, Konrad. A força normativa da Constituição, Tradução: Gilmar Ferreira Mendes, Sérgio Antônio Frabris Editor, Porto Alegre, 1991.

IGREJA CATÓLICA. Papa Francisco. Fraternidade, fundamento e caminho para a paz. $1^{\circ}$ de janeiro de 2014. Disponível em: http://www. vatican.va/content/francesco/pt/messages/peace/documents/papa-francesco_20131208_messaggio-xlvii-giornata-mondiale-pace-2014.html. Acesso em: 30 mar. 2020

MACHADO, Carlos Augusto Alcântara. A fraternidade como categoria jurídica: fundamentos e alcance (expressão do constitucionalismo fraternal). Curitiba: Appris, 2017.

MACHADO, Clara. O princípio jurídico da fraternidade: um instrumento para proteção de direitos fundamentais transindividuais. Rio de Janeiro: Lumen Juris, 2017.

MARTINI, Sandra Regina. Direito Fraterno na Sociedade Cosmopolita. In: RIPE - Revista do Instituto de Pesquisas e Estudos, Bauru, V. 1, N. 46, P. 119-134, jul./dez.2006. Disponível em: https://core.ac.uk/download/ pdf/79069559.pdf. Acesso em: 22 out. 2020.

MARTINI, Sandra; JABORANDY, Clara Cardoso Machado; RESTA, Eligio. Direito e Fraternidade: a dignidade humana como fundamento. In: Revista do Direito, Santa Cruz do Sul,v. 3, n. 53, p. 92-103,set./ dez.2017. Disponível em: https://online.unisc.br/seer/index.php/direito/ article/view/11364. Aceso em: 22 out. 2020.

MEZZAROBA, Orides; MONTEIRO, Cláudia Servilha. Manual de metodologia da pesquisa no direito. São Paulo: Saraiva, 2009.

ONU. Declaração Universal dos Direitos Humanos. 1948. Disponível em: https://nacoesunidas.org/wp-content/uploads/2018/10/DUDH.pdf. Acesso em: 30 mar. 2020.

PIZZOLATO, Filippo. A fraternidade no ordenamento jurídico italiano. In: BAGGIO, Antonio Maria (org.). O princípio esquecido: a fraternidade na reflexão atual das ciências políticas. Vargem Grande Paulista: Editora Cidade Nova, p. 111-126, 2008. 
RESTA, Eligio. O Direito Fraterno. Santa Cruz do Sul: EDUNISC, 2004. RUIZ, Castor M. M. Bartolomé. A sacralidade da vida na exceção soberana, a testemunha e sua linguagem: (re) leituras biopolíticas da obra de Giorgio Agamben. Cardenos IHU, São Leopoldo, ano 10, n. 39, p.04-50, 2012.

\section{AUGUSTO CÉSAR LEITE DE RESENDE}

Doutor em Direito pela Pontifícia Universidade Católica do Rio Grande do Sul (PUCRS). Mestre em Direito pela Pontifícia Universidade Católica do Paraná (PUCPR). Especialista em Direito Público pela Universidade Sul de Santana Catarina (UNISUL). Professor de Direitos Humanos e Fundamentais no Curso de Graduação em Direito da Universidade Tiradentes (UNIT). Promotor de Justiça em Sergipe.

Endereço profissional: Av. Conselheiro Carlos Alberto Barros Sampaio, N. 505, Centro Administrativo Gov. Augusto Franco, Bairro Capucho, CEP 49.081-010, Aracaju/SE.

ORCID ID: https://orcid.org/0000-0003-1719-8685.

E-MAIL: aclresende@bol.com.br

\section{CARLOS AUGUSTO ALCÂNTARA MACHADO}

Doutor em Direito pela Pontifícia Universidade Católica de São Paulo - PUC/SP. Mestre em Direito pela Universidade Federal do Ceará - UFC. Especialista em Direito de Estado pela Pontifícia Universidade Católica de São Paulo - PUC/SP. Professor de Direito Constitucional dos Cursos de Graduação e Pós-Graduação Stricto Sensu da Universidade Federal de Sergipe - UFS (São Cristóvão-SE) e da Universidade Tiradentes - UNIT (Aracaju-SE). Procurador de Justiça do Ministério Público de Sergipe. 
Endereço profissional: Av. Conselheiro Carlos Alberto Barros Sampaio, N. 505, Centro Administrativo Gov. Augusto Franco, Bairro Capucho, CEP 49.081-010, Aracaju/SE.

ORCID ID: https://orcid.org/0000-0002-2834-9699.

E-MAIL:cmachado@infonet.com.br

Recebido: 20/05/2020

Aceito: 28/10/2020

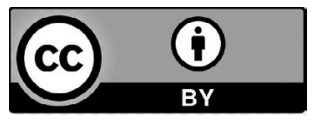

Este trabalho está licenciado sob uma licença Creative Commons Attribution 4.0 International License.

Autores e autoras cedem à Revista Sequência direitos exclusivos de primeira publicação, ficando o trabalho licenciado sob a Creative Commons Attribution 4.0 International License. A licença autoriza que terceiros remixem, adaptem e ou criem a partir do trabalho publicado, indicando o crédito ao trabalho original e sua publicação inicial. Os autores têm permissão para assumir contratos adicionais em separado, com distribuição não exclusiva da versão publicada na Revista Sequência, indicando, de todo modo, a autoria e publicação inicial neste periódico. 